\title{
Active Tolerance as a Collective Project: Global and Local Dimensions
}

\author{
Prof. Rafi Mann ${ }^{1}$, Dr. Oleksandr Khyzhniak ${ }^{2}$, \\ ${ }^{l}$ (PhD, Adjunct Associate Professor, Department of Communication - The School of Mass \\ Communication, Ariel University, Israel) \\ ${ }^{2}$ (PhD in Sociology, Associate Prof., Department of Applied Sociology and Social Communications, \\ School of Sociology, V. N. Karazin Kharkiv National University, Ukraine and fellow of Masa-16 at Ariel \\ University (Israel)
}

\begin{abstract}
The article is overthinking the limits of tolerance, the implementation of the principle of tolerance at different levels, the need for collective designing the active tolerance are justified. The author notes that active tolerance as a collective project, firstly is implemented in response to the social order of the modern society and its institutions, and secondly, is the ideological context caused by democratic ideology. The necessity of tolerant interaction support at personal and institutional levels is proved. To minimize the risks of conflicts and lower tensions on different grounds we propose to implement the principles of active tolerance. The readiness and potential positive effects of introducing special courses is shown. These courses should be devoted to the active tolerance at universities for the participants from post-Soviet countries.
\end{abstract}

Keywords -tolerance, tolerant social space, collective project, university.

\section{INTRODUCTION}

Tolerance is considered as characteristic of social interaction, as manifested in the ability to establish and maintain by peaceful means the communion between actors if there are social inequalities that violate it. Social tolerance is due to social and socio-cultural context of the environment in which it is perceived, formed and developed as a value, cultural norm and principle of activity.

At the turn of XX-XXI centuries. tolerance issue was actively reported both in theoretical and in practical world politics and scientific concepts. "So, the UNO following the initiative of UNESCO proclaimed 1995 to be the International Year of Tolerance, the result of which was the adoption of the Declaration of Principles on Tolerance. From that time, November 16 has become the International Day for Tolerance. In 2001, UNESCO proclaimed the beginning of the International Decade of Culture of Peace and Nonviolence. The principles of tolerance, as well as fundamental rights and freedoms enshrined in the laws and regulations, are inscribed in international declarations (for example, General Declaration of Human Rights and the International Covenant of Economic, Social and Cultural Rights). Within the framework of the Council of Europe there is the European Convention for the Protection of Human Rights and Fundamental Freedoms" [1].

We criticise those who believe that tolerance applies to all the positive and intolerance correlates with all the negative. Non-tolerance (or the more common term "intolerance") and tolerance have a greater function than act as polar opposites. Between them there is a dialectical relation which involves mutual transitions in particular timespace, so they can only be analysed in a given context. The opinion was popular some time ago that tolerance is always passive, meaning only the outer curb their attitude to the "another" cannot change the position of intolerance that may be unmotivated and idle. Currently, there is an urgent demand for active social tolerance. Active social tolerance is treated by us as social groups and communities' actions (including the representatives of management and power groups) aimed at practical implementation of tolerance as a value, cultural norm and principle of the social interaction within a specific social time and space. Active tolerance is not just the absence of hostility, aggression, but also interested attitude towards people of other nationalities, acceptance of the fact of their existence, the desire to understand and relate to. Thus, the feasibility of tolerance in a particular society depends on social, cultural and legal traditions, the general culture of people, and a reasonable, prudent policy of the ruling elite. This does not exclude the role of external factors such as the level of civilizational differences and international cooperation.

Nowadays, there is a growing demand for practical social technologies to tackle tolerant relations on different levels of social interactions, including global and local level. Such technologies are effective in the presence of scientific support, because otherwise they will not reach the goal and become anti-technologies. Technologisation of tolerant relations requires consideration in terms of construction and design. Therefore, this article will consider the following two main issues: 
- What is the reason of the transition from call for tolerance to demand of a collective design of active tolerance in the global context?

- What is the specificity of active tolerance implementation as a collective project in local practices (for example, education)?

Thus, tolerance as a value, norm and the principle of action, requires new look at both theoretical concept and practical guideline.

\section{OVERTHINKING SOCIAL PRACTICES AND THEORETICAL} APPROACHES TO THE TOLERANCE STUDIES.

In the majority of publications in recent decades, tolerance as public value, norm and principle has been thought of as a positive, natural and necessary element of building a liberal democratic society. Thus, Prof. Betty A. Reardon says that "tolerance is the very core of social responsibility in a pluralist society. It is the concepts and standards of human rights that specify the forms and goals of social responsibility which designate what conditions are intolerable and what behaviours are to be restrained" [2].

Rethinking tolerance throughout the European and the Middle East countries today due to new practices and challenges among which can be mentioned:

1. The migration crisis in the world as a result of the "Arab Spring", the continuation of military operations in Syria and the threat of ISIL / IS.

2. Practical implications of multiculturalism policy in the EU. The leaders of the EU member states are increasingly criticising, for example: David Cameron has criticised "state multiculturalism" in his first speech as prime minister on radicalisation and the causes of terrorism in 2011 [3]; Angela Merkel [4]; Nicolas Sarkozy $[5]$.

3. State-building of the post-Soviet republics, where the question of establishing the rules of interaction between different ethnic, religious and other groups on local, national, international and, as a consequence, international levels has become a stumbling block. It can be seen using the examples of the Russian Federation, Ukraine, Moldova, etc., where for the past 25 years, these lines of tension have transformed into various forms of conflict, including armed opposition.

4. Simmering conflicts in these areas, with different levels, for example, Israel: cooperation with neighbouring Arab countries, questions of inner-Israeli interaction between different ethnic and religious groups, etc.

Individual and collective forms of humans' existence and mechanism of their formation caused by various factors: historical and personal experiences, cultural, social, economic, political, religious factors etc. The individual and the collective forms represent humans' behaviour throughout life.

The processes of individualisation of modern societies are changing the forms of social life and social relations in the direction of pluralistic values and regulatory environment in which individual and collective are not dominated one on the other and obligatory interconnected. So, we have to break traditional frameworks of the opposition collective-individual through the interpretation of a social reality not as granted, but as a result of construction [6].

Actualisation of tolerance in science and its recognition as a global problem of modern civilization was preceded by a certain evolution of the understanding of this social phenomenon, which is most fully described by M. Walzer [7]. Tolerance is now regarded as a cultural, social and personal value [8], sometimes as a purely moral ideal [9], or as the good-in-itself [10]. It is believed that it is an important value of the civil society [11]. One thing is certain - different times and general cultural ethical principles have determined the parameters of tolerance. Tolerance has become a measure of the stability and reliability of a complexly structured social system at any level. In addition, it receives political support [12] in the modern world.

The study of the phenomenon of tolerance in recent years has allowed identifying the following definition [13]: tolerance is considered to be a characteristic of social interaction, which manifests itself in the ability to establish and maintain by peaceful means the commonness between the subjects in the presence of social inequalities that violate it. Tolerance is due to the social and socio-cultural context of the environment in which it is adopted, it is formed and referred as a value, cultural norms and principles of activity. The function of tolerance is revealed through the allocation of its following functions: social-integrating; identifying, humanitarian, trunking function, regulatory function of legitimation and appropriate actions (shares) of the state.

The idea of tolerance comes from the history of philosophical concepts. The problem of tolerance in ancient times generally attributed to the understanding of the concept of suffering and fate, because there was in fact no tolerance for the interpersonal level itself [14].

Nowadays, in the public opinion there are the following common interpretations of tolerance: tolerance as patience; tolerance as a leniency; tolerance as an extension of their experience and critical dialogue; tolerance as freedom; tolerance as impossibility of understanding; tolerance as indifference [15]. Different theoretical approaches to the definition of "tolerance" have been generalised by N. Pobeda, who identifies the following 
interpretations of tolerance: 1) modal stoicism - a fundamental recognition that another person has a "right", or - "the approval of differences"; 2) moral ideal of "tolerance goodness as relations"; 3) the correspondence of the "theory of good" (as socially significant and tolerance base) and human rights; 4) "the balance of judgment"; 5) temporary balance of power between the conflicting groups and values; 6) way to achieve peaceful coexistence; which means claiming other values - freedom, equality, justice; 7) the values and social norms of civil society [16:16].

Ronald Inglehart admits that democracy is closely connected with the types of values and culture in general: "democracy makes people healthy, happy, tolerant, so that they trust each other", "democratic institutions give rise to the self-expression values that are so closely linked with them. In other words, democracy makes people healthy, happy, tolerant, and trusting, and it instills post-materialist values (at least in the younger generation)" [17:94]. It is believed that democracy, together with positive values, is inherent mainly to the developed countries. Economic progress leads to democracy and democracy - to tolerance.

Particular attention should be paid to the concept of tolerance as respect, given by W. Schirmer, L. Weidenstedt and W. Reich: "Multicultural approaches that are based on the concept of tolerance or have the promotion of tolerance on their agenda run the risk of implicitly stating that their target clients, members of ethnic and racial minorities, are actually not welcome. The role of the state is rather ambiguous here. It regulates the potentially problematic behaviour of its majority citizens while, at the same time "being a tolerator" establishes (and maintains) a power hierarchy in which the tolerated one ends up in a subordinate position. Accordingly, subjects of tolerance are quite critical towards the concept and its practical implications. The concept of respect, by contrast, has properties that are far more appreciated by its recipients, and it therefore sends a more suitable message from multicultural policy programmes to its recipients. The move from tolerance to respect would also require policy changes. In contrast to tolerant policy, respectful policy does not simply decide paternalistically over people and throw demands at them. It listens and offers elbowroom and influence; in sum, it treats people as agents. Of course, the latter cannot be without conditions attached. In concrete situations, it would have to be decided individually who can get which possibilities and influence. The latter would depend on which agential claims can be agreed on to be legitimate" [18].

Meanwhile, each act of tolerance should have its borders. J. Habermas admitted that the line of tolerance/intolerance is traditionally drawn in an authoritarian manner: "Each act of tolerance must circumscribe a characteristic of what we must accept and thus simultaneously draw a line for what cannot be tolerated. There can be no inclusion without exclusion" [19]. So, each act of tolerance should have its "lines" of borders. Thereby, in Israel and Ukraine such "lines" of borders are essential for societies. More importantly, the existence of such essential borders of tolerance leads to the appearance of multiple forms of individual and collective in a multicultural space. It's manifested in various ways: identity, behaviour, worldview etc. as the result of complex and lifelong process of socialization.

Key actor of socialisation is the institution of education that translated knowledge, values, models of behaviour etc. Important part in this process belongs to universities that shape the personality after school, Israeli Defence Forces / Armed Forces of Ukraine. For many years universities have been the centres of intellectual and cultural life in the cities they are situated in and the country in a whole. Nowadays there is an increasing role of universities in building a tolerant society that meets modern values and norms. However, the role and the directions of the impact of university education and the possibility of implementation of individual and collective interests and rights of students in the optics of tolerance is still a little-investigated topic in the social sciences. For modern society, non-linear development is typical, tolerance limits are not established, they are open. Tolerance is developed as a culture of being in a non-guaranteed, complex, rich with social inequalities environment, where the actors realise that their identity (originality, uniqueness) can only take place through keeping the identity of "Other", through a dialogue between equals.

Intolerance is promoted by propaganda of violence, aggression, xenophobia through the media, the formation of social stereotypes perception of specific groups (religious, national, etc.) as hostile to a particular society. In addition, the excluded from economic and political life social groups provide risk groups while exposed to manifestations of social intolerance. "The most hopes for the implementation of tolerance "the weaker", who directly benefits from it. Tolerance is designed to hide their vulnerability. While "stronger" does not need the benefits of tolerance. It is for the latter a feature of self-restraint. However, it may happen that today those who are "weak", next day can become "stronger" and those who now are "stronger", could be "weaker" the next day. Tolerance provides a discourse of perspective thinking and considering this possibility" [20:15-16].

Today, the demand is not just for tolerance as coexistence with the "another", but namely "active tolerance". We consider that active tolerance can be described as a system of three subsystems (see fig. 1).

Fig. 1: Tolerance as a System. 


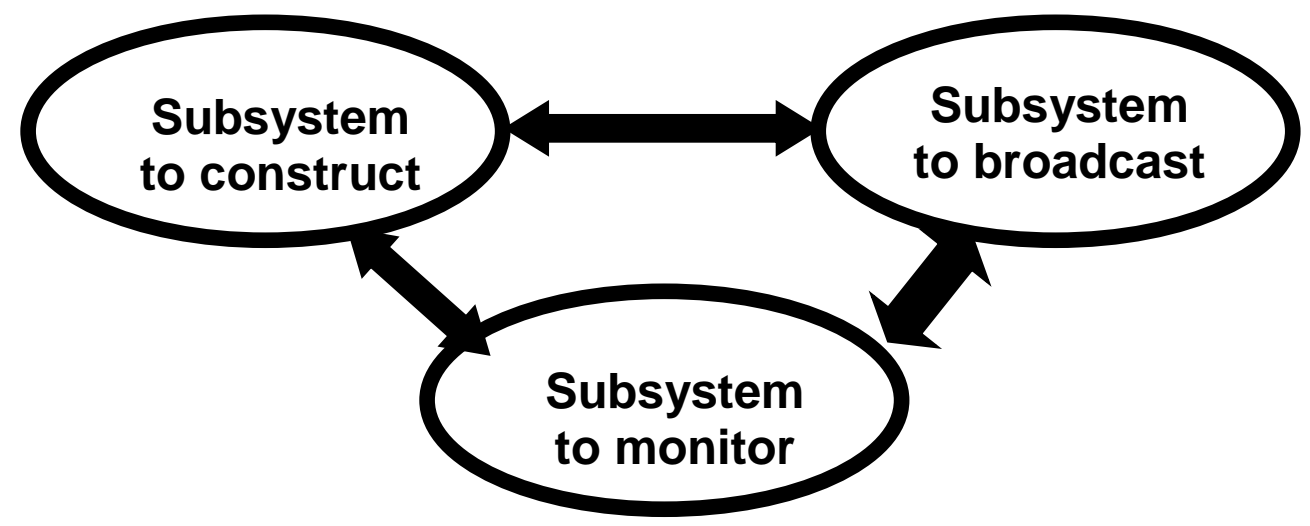

Source: the authors of the paper.

In this context, the active tolerance acquires the features of the system of institutionally organised forms of interaction. Consistency of manifestations of tolerance assumes stable algorithm manifestations of tolerance as a collective project, which must have at least three components [13]: design, broadcast and monitoring the implementation of tolerance. Thus, active tolerance must be institutionalised. In the functioning of such tolerance the existing social institutions can play a key role, which can be classified according to the role in the design, monitoring and broadcasting:

- The first subsystem consists of institutions that "construct" tolerance as a cultural, social and personal value (this is, first of all, institutions of science, law, politics, religion).

- The second subsystem includes institutions broadcasting (transmitting) a tolerant view of the world, form tolerant competence (this is, above all, the family, education, mass media).

- The third subsystem is the institutions that monitor compliance with the principles of tolerance in society. Mostly we mean the institutions of law, the state of public opinion. We emphasize that the legal and moral legitimacy tolerance without involving communication mechanism are hardly possible in practice.

After all, at all stages of the life cycle namely because of communication people get an opportunity to experience tolerance to themselves and tolerantly treat those whose ideological, intellectual, aesthetic and other views they do not share, but admit their existence, when it meets the basic values and norms of a particular society. Tolerance implies the existence of differences, a certain border between "us" and "others" (although this limit is not determined once and for all, it is moving). Collective design of tolerance at the institutional level implies that, first, this process each of the mentioned social institutions will comply with the particular functions and secondly, between social institutions there will be interaction, dialogue and coordination.

Thus, now the borders of tolerance are exposed to overthinking, the need for active tolerance and for its collective design is considered.

\section{NEED OF COLLECTIVE DESIGNING OF ACTIVE TOLERANCE: GLOBAL CONTEXT}

Considering the active tolerance as a collective project, we rely on the approach of V. Lukov, who refers to the social projects various projects affecting social life with their consequences [21]. Tolerance is a special object of social engineering. The collective subject of this design is the institutions, groups, communities, tolerant components of the social space. Collective design of active tolerance is a social technology, which aims at the formation and development of a tolerant social space. Tolerance as a collective project is a purposeful process of constructing tolerance as a cultural norm, value and a principle of social interactions, as well as broadcasting and control over their implementation in various social communities.

At the group level, tolerance design includes the actions to comply tolerant social relations in the local tolerant space limited by functioning of a particular social group.

Tolerant space design algorithm includes the following steps (universal): 1) analysis of the state, the level of tolerance in the certain community (group); 2) identification of social needs, the demand for tolerance; 3 ) organisation of project activities with the involvement of all collective actors (institutions and groups, communities); 4) monitoring the implementation of the project and evaluation of its results.

Today the idea of tolerance is in demand globally. It is known that different social environments are differently moving toward tolerance. As socio-cultural reality, it first emerged in Western Europe, which actually developed the first concept of tolerance (both religious and secular).

As we consider tolerance to be a special type of social interaction, the question is, what types of interactions promote it. Let's take for the basis the most common classification of the types of interactions, 
where can be found the following interactions: natural (they are the bases for such associations as population), emotional (become foundations of the communities), language and communication (cover community), activity (without them there is no society), legal, on their ground the state functions [22:10]. Social tolerance is created, maintained and reproduced by all of these types of interactions, but the leading one, we believe, is an activity interaction. Namely the latter creates (virtually and really) tolerant social environment. Thus, we can say there is the demand for active tolerance, by which we mean the action of social groups and communities (including the representatives of management and power groups) aimed at practical implementation of the principles of tolerance in social interaction within a specific social time and space.

Active tolerance as a collective project can take many forms, performing defining functions. Most systemic tolerance functions are described by M. Matskovskij, who identified them in relation to the subjects of tolerance [23: 43]. We share the idea that the function of tolerance / intolerance is due to the socio-historical conditions and the specificity of the operation of a particular social institution and a particular social group.

Social aspects of tolerance can be seen in the wider context: tolerance in the context of globalisation, detraditionalisation, late modernisation, cultural pluralism and diversity, increasing reflexivity. We share the interpretations of tolerance, primarily as overcoming social discrimination in all its forms. Tolerance is the ability to establish and maintain a unity of people, among whom there are social inequalities, provided that the latter do not conflict with adopted in a particular community moral and legal standards and democratic procedures during social interactions. Active tolerance may become a necessary construct for normalisation and harmonisation of social relations in a global context.

\section{ACTIVE TOLERANCE IN LOCAL PRACTICES AS A COLLECTIVE PROJECT(CASE-STUDY IN TERMS OF THE PARTICIPANTS OF MASA-ARIEL)}

\subsection{Peculiarities of Active Tolerance Development in Local Practices.}

Let's consider the peculiarities of functioning and development of tolerance as a collective project in terms of education as a local practice. In our opinion, it is necessary to distinguish between the two aspects of university's role in the direction of increasing tolerance: one is connected with the tolerant practices in the university environment, the second - in society as a whole. That is, we can talk about students' being within the university through the prism of correspondence "tolerance-intolerance" as well as the possibility of real influence of the university education institution on the condition of tolerant relationships outside the university as an institution through scientific, educational and PR activities.

The scientific and educational activities of the university towards a tolerant society is currently insufficient. This is crucial to search for answers to the following questions:

- what determines the tolerance and intolerance in social relations;

- which forms and types of tolerance dominate in the modern university;

- what are the characteristics of tolerant and intolerant practices and possibilities of adjustment towards increasing tolerance;

- the degree of tolerance in a university setting, motivation to the tolerant social behaviour of university education members; obstacles along the way;

- university's needs in the curriculum, extra-curricular events that promote tolerance in society;

- factors affecting tolerance at university, especially the technology to neutralise their actions.

According to numerous observations of student community, the signs of intolerance are manifested in (though only slightly) primarily in language and stereotypical estimations of the representatives of various groups. The Convention against Discrimination in Education (Paris, 14 December, 1960) maintains at the article 5 that "education shall be directed to the full development of the human personality and to the strengthening of respect for human rights and fundamental freedoms; it shall promote understanding, tolerance and friendship among all nations, racial or religious groups, and shall further the activities of the United Nations for the maintenance of peace" [24]. It is difficult to overestimate the role of universities in addressing the symptoms of intolerance in social life that can be seen as a contribution to higher education in the formation of a tolerant social space. In terms of enhancing the role of media in the lives of individuals and groups, higher education institutions are designed to overcome linguistic forms of intolerance (the so-called "hate speech") discourse of hate (aggression, irrationality, manipulativity). University contribute to the construction of a tolerant space, on the one hand expanding the boundaries of tolerance, and on the other setting its borders as essential need for keeping social, ethnical, religious and others identities of students through certain communicative technologies, training and research activities, PR-practices etc.

We offer to consider the possibilities of constructing an active tolerance in terms of the study of the participants of the project MASA-16 at Ariel University (Israel).

\subsection{Research Objectives and the Methodology of the Survey}


The aim of the survey is to identify the role of tolerance in daily life social interactions. The main hypothesis for empirical survey: tolerance as value, norm and principle of action are supported and manifested among group participants of MASA-16 at Ariel University.

Methodology (briefly) - quantitative sociological survey was used, namely the case study of the group of students as participants of MASA-16 Ariel with the help of a prepared question list (semi-closed questions). Additionally, all respondents could right their comments on each question, which were analysed after the survey was finished. 54 persons were interviewed among 61 participants, so more than $88 \%$ of all participants were interviewed. All respondents were asked to fill the questionnaire anonymously. We controlled next characteristics: age, sex, country of origin and specialization at Ariel University. The rest persons, who were not interviewed, have the same controlled characteristics as interviewed group, so the results of this survey are representative, accurate and valid.

MASA-16 participants are the group of youth from the Post-Soviet countries that came for a short-term period to study different subjects and travel around Israel to get acquainted with its culture and history. The group of respondents consists of $54 \%$ of women and $46 \%$ of men; $27 \%$ under 22 years, 39\% are $22-25$ years and the rest 34\% are 26-30 years; more than 55\% graduated from university (BA or MA), each fifth student either studies at BA programme in the country of origin, or finished school and hasn't entered the university; $37 \%$ follow Christianity, each third don't follow any religion, each fifth student follows Judaism, the rest refused to answer; $48 \%$ came from the Russian Federation, 42\% - from Ukraine, the rest - from other countries; $55 \%$ identify themselves as Jewish, Russians and Ukrainians $22 \%$ each, the rest identify themselves as other nationalities; $45 \%$ study management, $45 \%$ - mass media and 10\% - individual scientific research; $39 \%$ of students had the same specialty in the country of origin.

\subsection{The Results of Empirical Research}

The main hypothesis for empirical survey has been partly proved. Tolerance is declared as a norm in the context of "right answer", but not a value and the principle of activity among the participants of MASA-16 at Ariel University.

It has been identified that tolerance is an important quality that can lead to success in life, according to the opinion of our respondents. This quality achieved index 3.66 of importance. In our survey we studied the factors of success in life. The respondents were offered a list of 39 qualities or they could add any quality by themselves. Respondents could evaluate each quality by one number from " 1 " as absolutely unimportant to " 5 " as very important, so tolerance with index 3.66 likely more important than not.

Prevalence of tension can provoke conflicts and intolerant social practices. According to our results, we didn't register high intensity of conflicts at a group level (see fig. 2).

Fig. 2: Prevalence of tension within MASA-16, in \% (answers to the question: "In your opinion, is tension typical or not between?..")

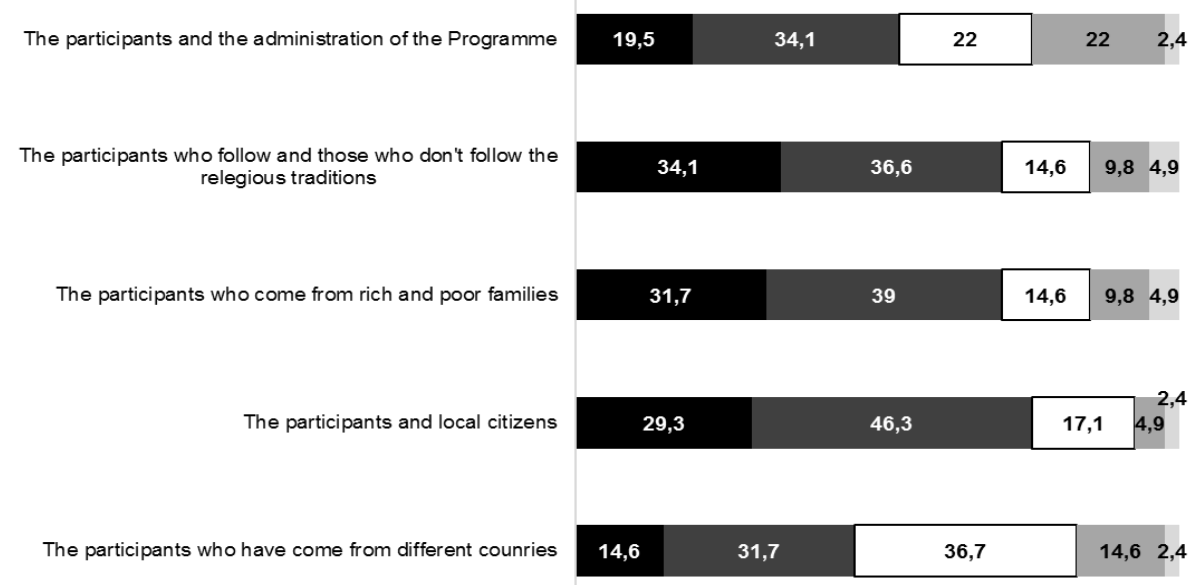

- Absolutely not typical $\square$ Mostly not typical $\square$ Sometimes typical, sometimes-no $\square$ Mostly typical $\square$ Absolutely typical

Source: the authors of the papers.

The group of participants don't register tensions as typical situation during their stay at the Programme MASA-16. So, we can say that the core of conflicts can be rather at individual, than group level; therefore technologies of preventing conflicts should be used at this level. In this case, the need to stimulate tolerance as a necessary individual quality is uprising. 
Common leisure, willingness to relax and entertain, trips, volunteering, bridge language and common overcoming the difficulties in everyday life are the main consolidating factors (see fig. 3). This group of factors is the most important for the younger participants. Difficulties in everyday life are the main separating factors (see fig. 4). In the comments respondents explain that political dimension that separates them has two aspects: 1) differences that can be named as support to "left"-"right" political wings; 2) different attitude toward situation at Eastern part of Ukraine and Crimea (between participants from Ukraine and the Russian Federation).

What should be done to establish effective and peaceful social interaction? MASA-participants offer several needs to be provided by them and by the Programme (see fig 5). Tolerance as a principle of interaction has the $3^{\text {rd }}$ position for the participants as a core need $(43.9 \%)$. On the other hand, possibility to productively spend their free time is the highest need for the participants $(51.2 \%)$. This answer totally correlates with the consolidating factors, such as "common leisure", "willingness to relax and entertain yourself" "common trips and volunteering work" (more than $90 \%$ pointed that positions in both questions). The $2^{\text {nd }}$ need is "better awareness of their rights" (46.3\%).

Fig. 3: Consolidating factors, in \% (answers to the question: "What, in your opinion, brings together the participants of the programme MASA-16?")

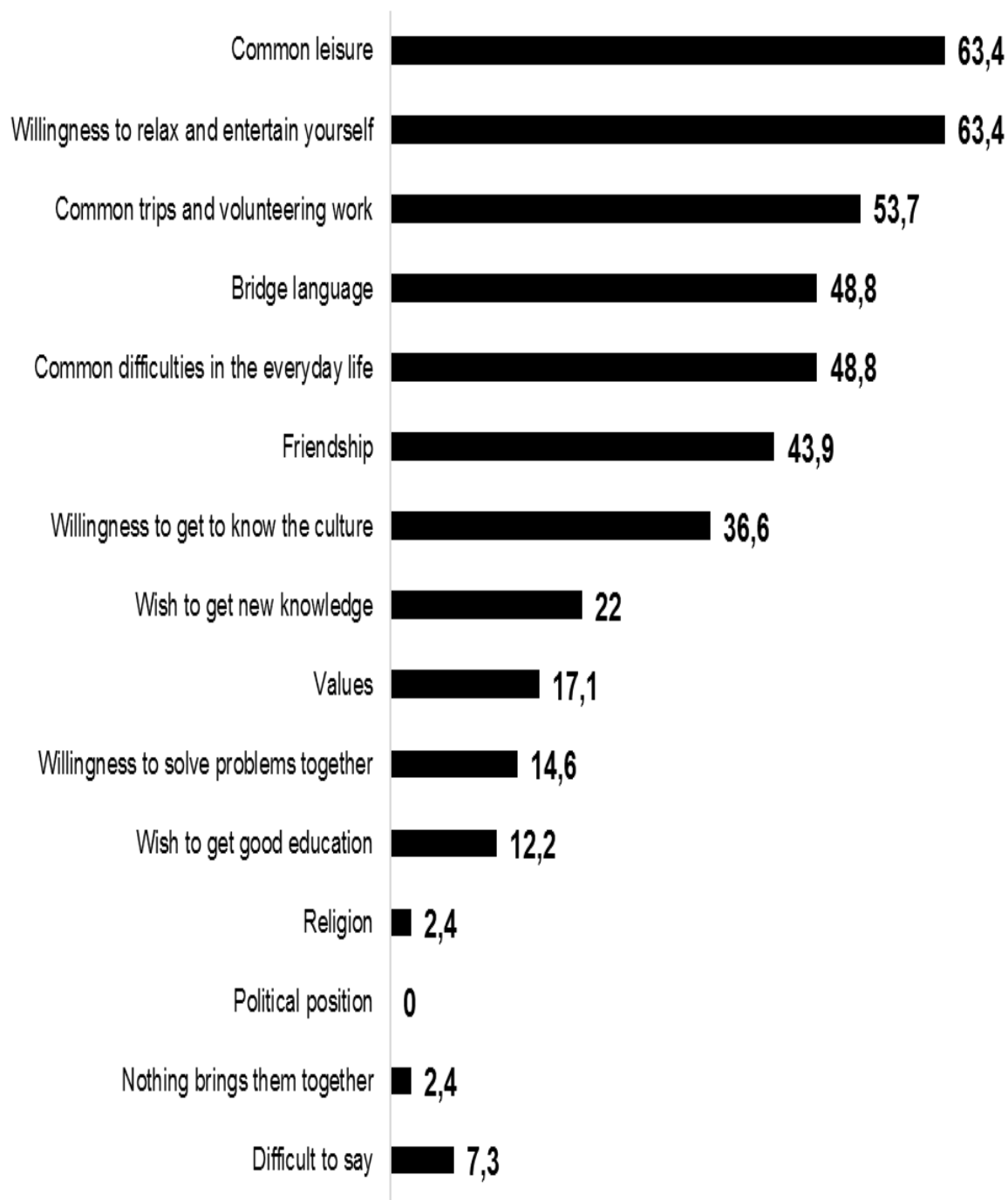

Fig. 4: Separating factors, in \% (answers to the question: "What, in your opinion, separates the participants of the programme MASA-16?") 


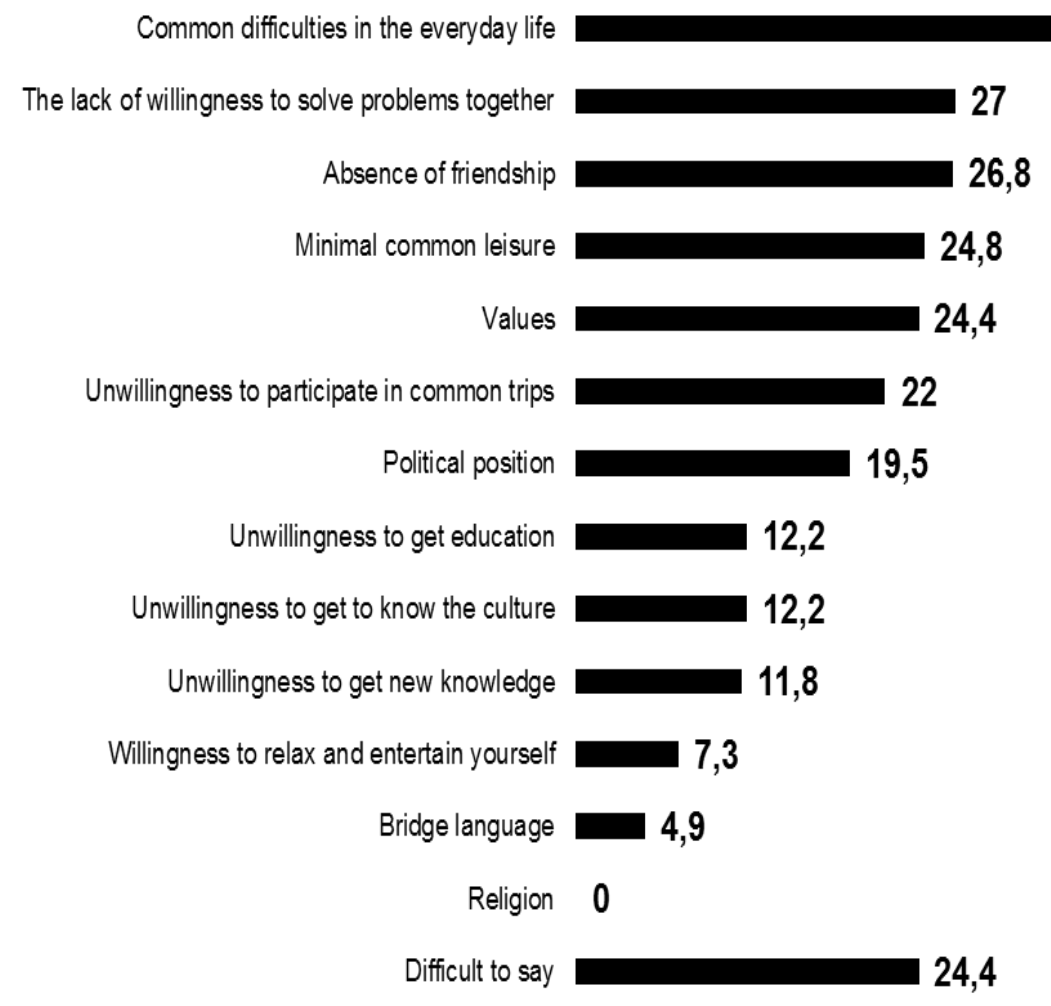

Source: the authors of the papers.

The results show that the need for tolerance is declared at the high level in this group. Nevertheless, the MASA-participants have different opinions toward to which social groups tolerance should be taught with the help of university (see fig. 6). We have figured out that religion and gender are not the separating factors, but it can't indicate that we have active tolerance. In the comments to the questionnaire respondents have written that during their stay at Ariel University between each other they don't feel tensions, conflicts on religious or gender ground, but in other situation, especially in the country of origin, such examples are not rare. Another situation with the political stance: different political positions one of the main separating factor as we figure out at fig.4. At the same time, most of participants understand the necessity of the tolerance to be taught at university to avoid such factor as separating. Respondents have different opinions about teaching tolerance toward the representatives of the LGBT-community: 45\% support such idea in general, $27.5 \%$ don't support such idea and the rest $27.5 \%$ in some cases support this idea, and in some - don't.

Moreover, the respondents mentioned that at their home universities they almost didn't have any courses or trainings concerning tolerant social interaction, so experience in Israel would be useful for all the participants of interactions.

Fig. 5: What the participants of MASA-16 need, in \% (answers to the question: "What do you think, to what extent the participants of the programme MASA-16 need or not the following?") 
Possibility to productively spend their free time Better awareness of their rights

Tolerance toward each other Improving amenities

The events, which would help to get to know each other better

More frequent tourist and cultural trips in Israel Establishing a dialogue between the madrichs and the participants of the Programme

The paticipants' respect for the obligations Better awareness of their duties Communication with local citizens

Communication with the students of Ariel University Establishing a dialogue between the administration of the Programme and the participants

Initiative and independence in solving everyday problems

Changing attitude towards local citizens

More frequent volunteering work

Changing attitude towards the students who have come from different countries

The paricipants' higher activity in assertion of their rights
51,2

46,3

43,9

43,9

39

39

36,6

34,1

31,7

31,7

29,3

26,8

\section{6,8}

\section{4,6}

9,8

7,3

7,3

\section{Other $\square 2,4$}

Source: the authors of the papers.

Fig. 6: Tolerance toward what groups should be taught at universities..., in \% (answers to the question: "Is it necessary or not to teach tolerance to students?")

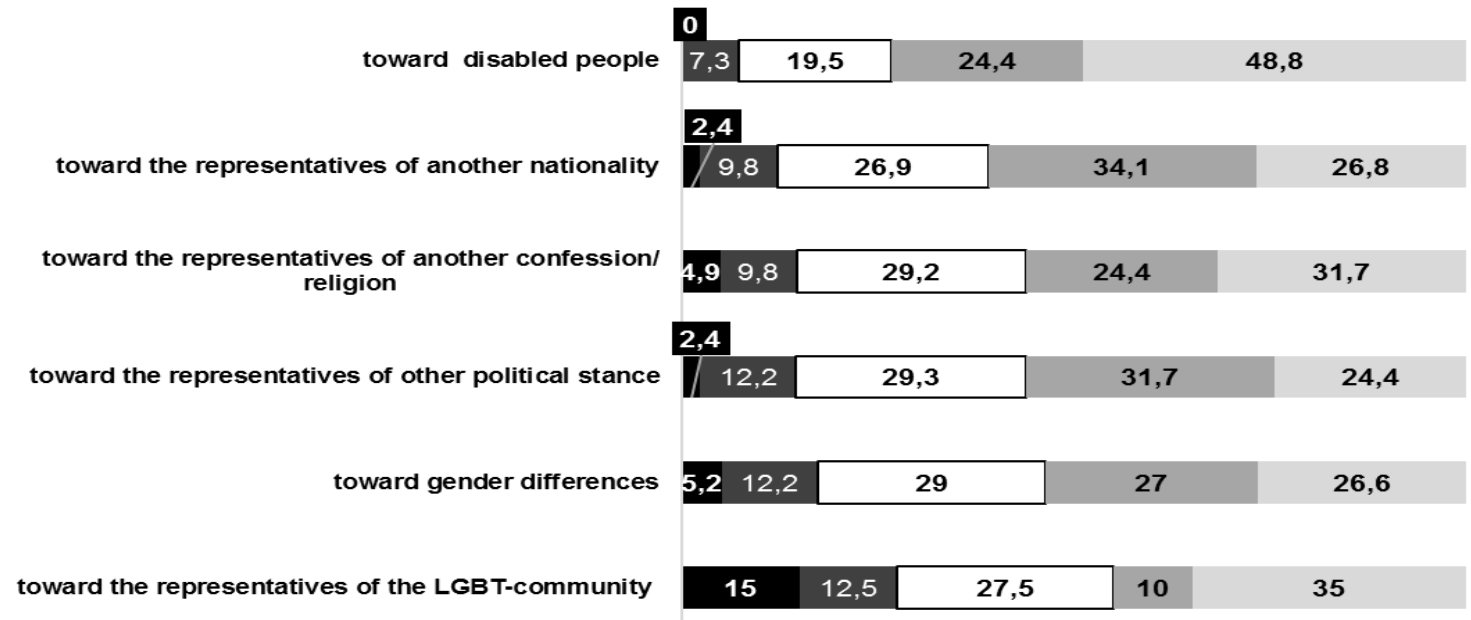

- Absolutely NO $\square$ Mostly NO 口In some cases yes, in some-no Mostly YES Absoletely YES

Source: the authors of the papers. 
Contradictory answers were registered in the question of teaching tolerance toward representatives of another nationality: on one hand the idea to teach tolerance at university, as we mention before, is supported by $60.9 \%$, but on the other hand not to all nations our respondents have the same attitude. We asked several additional questions (open question): what feelings/emotions they would have if they become eyewitnesses of humiliate Jews / Arabs? What will they do in both cases? And in general representative of what nationality they would protect and whom they won't protect in any cases (see tabl. 1). The results show, that tolerance is mostly declared as a norm, as a "right answer", but yet not a core value or principle of action.

Table 1

Feelings and Actions as Eyewitnesses of Humiliation (results of analyses open questions)

\begin{tabular}{|c|c|c|c|}
\hline \multicolumn{2}{|l|}{ Jews } & \multicolumn{2}{|l|}{ Arabs } \\
\hline $\begin{array}{l}\text { Feelings/emotions as } \\
\text { eyewitness of humiliation }\end{array}$ & Actions & $\begin{array}{ll}\text { Feelings/emotions } & \text { as } \\
\text { eyewitness } & \text { of } \\
\text { humiliation } & \end{array}$ & Actions \\
\hline $\begin{array}{l}\text { apr. } 70 \% \text { - negative: } \\
\text { anger, irritation, rage, } \\
\text { offence, } \\
\text { aggressiveness toward } \\
\text { the offenders } \\
\text { apr. } 10 \% \text { neutral and } \\
\text { ignorance } \\
\text { - } \text { apr. } 10 \% \text { complicated } \\
\text { fewer than } 10 \% \\
\text { couldn't answer }\end{array}$ & $\begin{array}{l}\text { - } 65 \% \text { use } \\
\text { diplomatic } \\
\text { ways to } \\
\text { protect Jews } \\
\text { - } 15 \% \text { can use } \\
\text { force against } \\
\text { offender } \\
\text { - } 10 \% \text { no } \\
\text { actions, try } \\
\text { to avoid } \\
\text { personal } \\
\text { involves } \\
\text { - fewer than } \\
10 \% \\
\text { couldn't } \\
\text { answer }\end{array}$ & 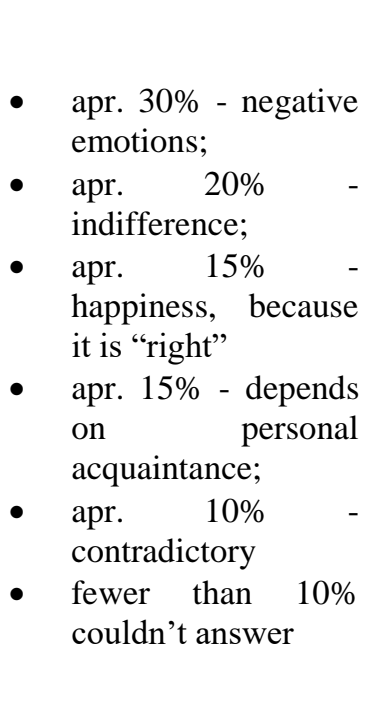 & $\begin{array}{l}\text { - apr. } 40 \% \text { no } \\
\text { actions, try to } \\
\text { avoid } \\
\text { personal } \\
\text { involves } \\
\text { - apr. } 30 \% \text { use } \\
\text { diplomatic } \\
\text { ways to } \\
\text { protect Jews } \\
10 \% \text { help to } \\
\text { humiliate } \\
\text { Arabs in any } \\
\text { case; } \\
10 \% \\
\text { indifference; } \\
\text { fewer than } \\
10 \% \text { couldn't } \\
\text { answer }\end{array}$ \\
\hline
\end{tabular}

Source: the authors of the papers.

Most of the respondents who declared to do some action to protect Jews added that their action doesn't correlate with the nation aspect: they will try to help anyone. But when the question was about Arabs, we recorded half fewer answers with such a comment. It can be the results of influence of two main factors: the respondents share previous idea toward Arabs, too or they have negative stereotypes toward another nation (it should be checked in further surveys). 1/3 admitted that their reaction can change, depending on situations, and about $15 \%$ insist, that they see no problem in national dimensions of conflicts, because "good or bad people exist within any nation".

Nowadays it seems that the word 'tolerance' lives by Orwell's scheme, only in reverse: the nomination is declared, but the public mind is not attributed, and actions - both verbal and non-verbal - are not always consistent with the principles of tolerance. In our opinion, overcoming this gap is possible by designing the active tolerance as a value, norm and principle. Local communities that are characterised by intense intra-group interactions are subject to a variety of challenges that can provoke conflicts as intragroup and intergroup [25]. An example of a group of the participants MASA-16 at AU as the local community demonstrates the relevance of the active implementation of the tolerance principles, for which appropriate practical social technologies should be developed.

\subsection{The Key Findings}

Traditional approaches of understanding and implementing tolerance in practice has failed. Overthinking the concept of tolerance has led us to the transition to practical use of the active tolerance concept as a system consisting of three subsystems: constructing, broadcasting and monitoring tolerance. Active tolerance as a value, social norm and the principle of action should and can provide tolerant social space which will affect social interactions by the means of universities. Active tolerance should have borders which are historically and culturally caused.

Practical implementation of the active tolerance idea requires its technologisation with regard to local practices of big and small social groups. Empirical research of emerging tolerant space in terms of the 
participants of MASA-Ariel programme, who have both common and different, proves the necessity of a specialised approach to managing social interactions. We have figured out that the hypothesis for empirical research is partly proved: tolerance appeared as an "outside" characteristic, more declarative for the group of respondents from MASA-16 at Ariel University. It was found that the participants in the researched group declare the need to create and maintain a tolerant space within the group itself and in collaboration with others, see the potential of tolerance as a necessary personal quality and the need for its training, including through university. This group is traditionally created for a limited period of training involving the participants from different countries, age, religion, political or ideological views, that provokes the tensions and increases conflict potential.

Our results prove the necessity of using the education mainly by university resources in the formation of active tolerance through scientific, educational and PR activities. So, to minimise the risks of conflicts and to lower the tensions on different grounds, we offer to implement the principles of active tolerance as collective project. The readiness and potential positive effects of introduction of special courses devoted to active tolerance at universities for the participants from post-Soviet countries have been shown.

\section{CONCLUSIONS}

The concept of tolerance was first used in science at the time of the search for the ways and mechanisms of democratic society. Tolerance gradually turned into one of the democratic values, without which other values lose their practical sense. The democratisation of society is effective for the transition from tolerance as a "background" value to active tolerance.

Currently, the borders of tolerance are being overthought, the need for active tolerance in its collective design is realised.

Tolerance as a collective project is a purposeful process of manufacturing tolerance as cultural norm, value and principle of social interactions, as well as broadcasting and control over their implementation in various social communities. It naturally becomes a part of the value-regulatory system of society when accompanying social communication, which, in our opinion, firstly, supports pluralistic balance in society and creates the conditions for the formation of a tolerant social atmosphere, freedom of opinion and estimates that are necessary for the formation of reflective tolerance and transforming "another" into an equal partner; secondly, it reproduces democratic foundations without which the dialogue between "us" and "other" becomes impossible or hampered, along with understanding, development and implementation of human rights and groups; thirdly, the image of the "other" takes the perspective of "different", but not "the enemy"; culture itself in this communication is not seen as unity in diversity but as diversity of unities when the individual and the group appears the right to be different, and the this right is to some extent protected; fourth, it promotes the dialogue between different cultural and other groups, and also teaches compromise for the sake of social harmony.

Collective design of tolerance at the institutional level implies that, first, this process should involve the institutions that construct tolerance, transmit it and monitor compliance with the tolerance rules and principles; and each of the involved social institutions will comply with the functions, and secondly, between social institutions there should be cooperation, dialogue and coordination. At the group level, tolerance design includes actions aimed at keeping tolerant social relations.

In the collective design of a tolerant space a special place is taken by the institution of education, which is involved in the process of both production and broadcasting tolerance, and in monitoring its implementation. Since university education is considered to be an important element and the resource of information society, where the future professional identity and the loyal to the state institutions tolerant citizen is formed, social technology designed to create $t$ such a tolerant person is needed.

Empirical survey with MASA participants has figured out that tolerance is declared as a norm in the context of "right answer", but not a value and the principle of activity among the participants of MASA-16 at Ariel University, so the main hypothesis was partly proved. Tolerance is regarded as one of the important qualities in life success, has the third place in needs to be implemented in interpersonal or social interactions. It is identified that the participants have lower intensity of tensions at a group level between the main agents of interactions. In intergroup interactions there are a few separating factors, and they can provoke conflicts. Some of them are quite contradictory and can be replaced by consolidating factors, for example, attitude toward the way of spending leisure time is in 2.5 times more consolidating factor, than separating. But in some cases setting up new values and principles of interactions is the only way to solve and prevent conflicts. We consider that it concerns political questions at least in two dimensions: 1) in the conflicts of the countries of origins (for example, participants from Ukraine and the Russian Federation); 2) toward the group of Arabs, which is regarded as a group toward which tolerance is not even declared. 
As the result of our survey we concluded that it is especially needed to construct and expand tolerant social space mainly in three directions by the universities: construct and formulate the idea of active tolerance thru educational process; transmit and spread the idea by best PR-companies / actions / projects on different target groups; monitor compliance with the principles of active tolerance and its borders. Group of participants of MASA-16 at Ariel University is the example of target group with risk factors and immanent presence of tensions. Tolerance in this group appeared as "outside" characteristic, more declarative for the participants of MASA-16 at Ariel University. To minimise the risks of conflicts and to lower tensions on political ground, we offer to implement the principles of active tolerance. Readiness and potential positive effects of introducing special courses devoted to active tolerance at universities for the participants from post-Soviet countries has been shown.

In the future, it is advisable to focus on the scientific support of democratisation processes of different societies and forming tolerant social space by different collective actors. It should also be kept in mind that tolerance in the academic discourse is interdisciplinary in nature, since it requires legal, moral, economic, social, psychological, communicative justification. So it, as a collective project, requires comprehensive scientific support.

\section{ACKNOWLEDGEMENTS}

Generous support was provided by grant of the Project "Masa-Ariel University" (Israel) under supervising of prof. Nitza Davidovitch. Special acknowledgement to academic Vil Bakirov for his mentoring and support (V. N. Karazin Kharkiv National University, Ukraine).

\section{REFERENCES}

[1] O. Khyzhniak, Labirinty tolerantnosti (Kharkiv: KhNU imeni V. N. Karazina, 2014). (in Russian).

[2] B. A. Reardon, Tolerance: the threshold of peace (a teaching / learning guide for education for peace, human rights and democracy). UNESCO. Printed in France, 1994, [Electronic resource] :http://unesdoc.unesco.org/images/0009/000981/098178e.pdf

[3] D. Cameron, State multiculturalism has failed, says David Cameron. [5 February 2011; From the section UK Politics]. [Electronic resource] :http://www.bbc.com/news/uk-politics-12371994

[4] A. Merkel, German multiculturalism has 'utterly failed' [20 October 2010]. [Electronic resource] :https://www.theguardian.com/world/2010/oct/17/angela-merkel-german-multiculturalismfailed

[5] F. Sarkozy, Multiculturalism Has Failed [Friday, February 11, 2011]. [Electronic resource] :http://www.cbn.com/cbnnews/world/2011/february/frances-sarkozy-multiculturalism-hasfailed $/$ mobile $=$ false

[6] P. Corcuff, Les Nouvelles Sociologies: Constructions de la Réalité Sociale (Nathan, 1995). (in French).

[7] M. Walzer, 1997: On Toleration. Yale: Yale University Press, New Haven, pp. 126.

[8] V. Shalin, Tolerantnost: Culturnaya norma i politicheskaya neobhodimost (LAP LAMBERT Academic Publishing, 2011). (in Russian).

[9] A. Percev, Mentalnaya tolerantnost. Tolerantnost. Vestnik Uralskogo mezhregionalnogo instituta obshestvennyh otnoshenij, 1, 2002, 30-47. (in Russian).

[10] P. Nickolson, Tolerantnost kak moralnyj ideal, Tolerantnost. Vestnik Uralskogo mezhregionalnogo instituta obshestvennyh otnoshenij, 1, 2002, 97-111. (in Russian).

[11] S. Shajhitdinova, "K socialnoy tolerantnosti - cherez grazhdanskoe obshestvo" kak problema racionalizatcii rossijskogo mentaliteta. in L.Semina (Ed.), MY - sograzhdane (SMI $i$ obshestvo), 1 (Moscow: BONFI, 2002) 117-133. (in Russian).

[12] E. Solov`ev, Tolerantnost v politicheskoy istorii chelovechestva: predposylki ili product democratii, Mirovaya economika i mezhdunarodnye otnoshenia. 4, 2003, 112-119. (in Russian).

[13] O. Khyzhniak, Tolerantna socialna merezha: osobystisnyy ta instytucionalizovanyy aspect, Visnyk Odessa I.I.Mechnikov National University, Sociology and political sciences, 13(5), 2008, 243-249. (in Ukrainian).

[14] M. Benz, F. Felber, G. Naschert, ect., European Ideas on Tolerance (Krakow : Ksegarnia Akademicka, 2009).

[15] V. Lektorskij, Tolerantnost: kultura i vremya (Moscow: Publisher MGU, 2003). (in Russian).

[16] N. Pobeda, Tolerantnost: soderzhatelnye smysly i sociologicheskaya interpretacia. Socis, 6, 2007, 13-28. (in Russian).

[17] R. Inglehart, Culture and Democracy, in L. Harrison, S. Huntington (Eds.), Culture Matters: How Values Shape Human Progress (New York: Basic Books, 2000). 
[18] W. Schirmer, L. Weidenstedt, W. Reich, From tolerance to respect in Inter-ethnic contexts, Journal of Ethnic and Migration Studies, 38(7), 2012, 1049-1065, DOI: 10.1080/1369183x.2012.681448 .[Electronic resource] :http://dx.doi.org/10.1080/1369183x.2012.681448

[19] J. Habermas, Intolerance and discrimination, International Journal. Constitutional Law. 1(1), 2003, 2-12 DOI:10.1093/Icon/1.1.2

.[Electronic resource] :http://icon.oxfordjournals.org/citmgr?gca=ijclaw\%3b1\%2f1\%2f2

[20] A. Lopatka, Przycynek do pojmowania tolerncji, in M. Szyszkowkiej, T. Kozlowskiego (Eds.), Tolerancja. (Warszawa: Spoldzienia Wydawnicza «ANAGRAM», Fundacja Uniwersytetu Warszawskiego, 2003) 15-16. (in Polish).

[21] V. Lukov, Socialnoe proektirovanie (Moscow: Flinta, 2007). (in Russian).

[22] A. Boronoev, O poniatiah "obshestvo" i "socialnoe", Socis, 8, 2003, 3-11. (in Russian).

[23] M. Matskovskij, Tolerantnost kak ob`ekt sociologicheskogo issledovania, Vek tolerantnosti, 3-4, 2001, 40-52. (in Russian).

[24] Convention against Discrimination in Education (Paris, 14 December 1960). In: http://portal.unesco.org/en/ev.php-url_id=12949\&url_do=do_topic\&url_section=201.html

[25] L. Synelnikova. Role of the concept "Tolerance" in the formation of democratic society. [Electronic resource] :http://experts.in.ua/baza/analitic/index.php?element_id=11252 (in Russian). 